\title{
Transient stratification as the cause of the North Pacific productivity spike during deglaciation
}

\author{
Phoebe J. Lam ${ }^{1 \star}$, Laura F. Robinson ${ }^{1,2}$, Jerzy Blusztajn ${ }^{3}$, Camille Li ${ }^{4,5}$, Mea S. Cook ${ }^{6}$, \\ Jerry F. McManus ${ }^{7}$ and Lloyd D. Keigwin ${ }^{3}$
}

\begin{abstract}
During the Bølling-Allerød warm period of the last deglaciation, about $14 \mathrm{kyr}$ ago, there was a strong and pervasive spike in primary productivity in the North Pacific Ocean'. It has been suggested that this productivity event was caused by an influx of the micronutrient iron from surrounding continental shelves as they were flooded by sea-level rise ${ }^{2}$. Here we test this hypothesis by comparing numerous proxies of productivity with iron flux and provenance measured from a core from the subarctic Pacific Ocean. We find no evidence for an abrupt deglacial pulse of iron from any source at the time of peak productivity. Instead, we argue that the deglacial productivity peak was caused by two stepwise events. First, deep convection during early deglaciation increased nutrient supply to the surface but also increased the depth of the mixed layer, which pushed surface production deeper in the water column and induced light limitation. A subsequent input of meltwater from northern American ice sheets then stratified the water column, which relieved light limitation while leaving the surface waters enriched in nutrients. We conclude that iron plays, at most, a secondary role in controlling productivity during the glacial and deglacial periods in the subarctic Pacific Ocean.
\end{abstract}

Iron is a key micronutrient that limits primary production in the modern subarctic Pacific, equatorial Pacific, and Southern Ocean $^{3}$. Strong links between dust supply and opal flux in the equatorial Pacific over the past million years provide evidence that iron has also exerted a controlling influence over long time periods ${ }^{4}$, but its past role in other modern-day iron-limited regions is more equivocal ${ }^{5}$. The primary external iron sources to the modern subarctic Pacific are atmospheric deposition of Asian dust and volcanic ash, and submarine lateral transport from the surrounding continental margin ${ }^{6-9}$. Asian dust originates primarily from the old, weathered Loess Plateau in northern China ${ }^{10}$. In contrast, the continental margin surrounding the subarctic Pacific is young and volcanic. Because of the differences in these two source regions, mineralogical and geochemical techniques can be used to distinguish between the loess and volcanic sources of detrital material to the subarctic Pacific ${ }^{11}$. We tested the hypothesis of a continental margin-derived iron influx stimulating productivity by reconstructing the provenance and absolute flux of detrital material, and thus iron, to the western subarctic Pacific (WSP) since the Last Glacial Maximum (LGM). Within the same core, we also measured numerous proxies of productivity.

We sampled core GGC-37, collected from the western flank of the Detroit Seamount at $50^{\circ} 25.20^{\prime} \mathrm{N}, 167^{\circ} 43.90^{\prime} \mathrm{E}$ and depth
$3,300 \mathrm{~m}$ on the Akademik Vinogradov 19-4 cruise in $1991^{12}$. This location was chosen because it is close to the site of a mesoscale iron enrichment experiment that confirmed modern iron limitation of productivity ${ }^{3}$, it receives dust deposition from the Chinese Loess Plateau in the modern and LGM climate ${ }^{10}$ and it is near a water column study that confirmed a modern volcanic margin source of iron ${ }^{7}$.

The $\mathrm{Sr}$ and $\mathrm{Nd}$ isotopic compositions of the sediments in core GGC-37 vary coherently downcore with the least radiogenic $\mathrm{Nd}$ present during the deglacial section (Fig. 1a). The $\mathrm{Nd}$ isotopic composition varies between +3 and $-5 \varepsilon \mathrm{Nd}$ units and ${ }^{87} \mathrm{Sr} /{ }^{86} \mathrm{Sr}$ ranges from 0.70614 to 0.70842 . The $\mathrm{Sr}$ and $\mathrm{Nd}$ isotopic composition of GGC-37 samples generally fall on a twoendmember mixing line defined by a Kamchatka volcanic rock source (www.earthchem.org) and the residual detrital fraction of Asian loess ${ }^{13}$ (Fig. 1b). There are few isotopic data from the Bering Sea region (Fig. 3a), but data from the Yukon River, which drains into the Bering Sea, suggest that this region could also provide detrital material with a similar isotopic composition to Asian loess $^{14,15}$ (Fig. 1b and Supplementary Information); we thus refer to this isotopic endmember as 'loess-like'. The Nd-based detrital source reconstruction shows that volcanic-like material dominates (75-80\%) total detritus during the Holocene epoch, consistent with estimates for the modern WSP from surface sediments and sediment trap material $(60-85 \%)^{11}$. During the early deglaciation and LGM, the volcanic source accounts for about $60 \%$ of the total detritus and is at a minimum $(\sim 40-50 \%)$ in the middle and later deglaciation (Fig. 1c).

The absolute ${ }^{230}$ Th-normalized detrital flux is highest in the LGM and early deglaciation $\left(1.7-2.0 \mathrm{~g} \mathrm{~cm}^{-2} \mathrm{kyr}^{-1}\right)$ and drops through the rest of the deglaciation by a factor of 2-3 to the lowest values during the Holocene $\left(0.75 \mathrm{~g} \mathrm{~cm}^{-2} \mathrm{kyr}^{-1}\right.$; Fig. $\left.2 \mathrm{c}\right)$, consistent with DIRTMAP reconstructions of detrital flux to the WSP (ref. 16). Assuming a constant $130 \mu \mathrm{g}$ soluble Fe/g detritus (Supplementary Information), this input is equivalent to a soluble iron flux from detrital matter of $\sim 250 \mu \mathrm{g} \mathrm{Fe} \mathrm{cm}^{-2} \mathrm{kyr}^{-1}$ during the LGM and early deglaciation, decreasing to $\sim 100 \mu \mathrm{g} \mathrm{Fe} \mathrm{cm}^{-2} \mathrm{kyr}^{-1}$ in the Holocene (Fig. 2c). Holocene values are consistent with modelled estimates of pre-industrial soluble iron flux to the WSP of $30-160 \mu \mathrm{g} \mathrm{Fe} \mathrm{cm}^{-2} \mathrm{kyr}^{-1}$ (ref. 6). Like total detrital material, the fluxes of both volcanic-like and loess-like detrital material are highest during the LGM and decrease during the deglacial period to lowest levels in the Holocene. The flux of volcanic-like material drops by a factor of two to Holocene levels by $15 \mathrm{kyr}$ ago, whereas the flux of loess-like material stays elevated at LGM levels

\footnotetext{
${ }^{1}$ Department of Marine Chemistry and Geochemistry, Woods Hole Oceanographic Institution, Woods Hole, Massachusetts 02540, USA, ${ }^{2}$ University of Bristol, Wills Memorial Building, Queen's Road, Bristol BS8 1RJ, UK, ${ }^{3}$ Department of Geology and Geophysics, Woods Hole Oceanographic Institution, Woods Hole, Massachusetts 02540, USA, ${ }^{4}$ Geophysical Institute, University of Bergen, 5007 Bergen, Norway, ${ }^{5}$ Bjerknes Centre for Climate Research, 5007 Bergen, Norway, ${ }^{6}$ Department of Geosciences, Williams College, Williamstown, Massachusetts 01267, USA, ${ }^{7}$ Lamont Doherty Earth Observatory, Columbia University, Palisades, New York 10964, USA. *e-mail: pjlam@whoi.edu
} 


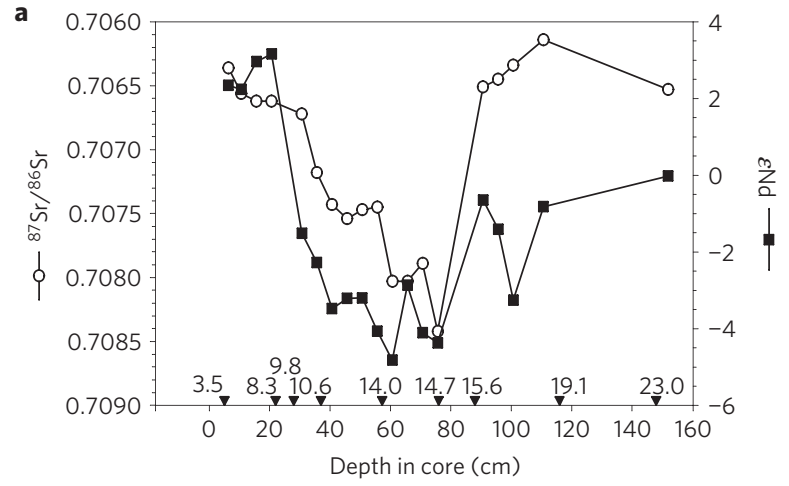

b

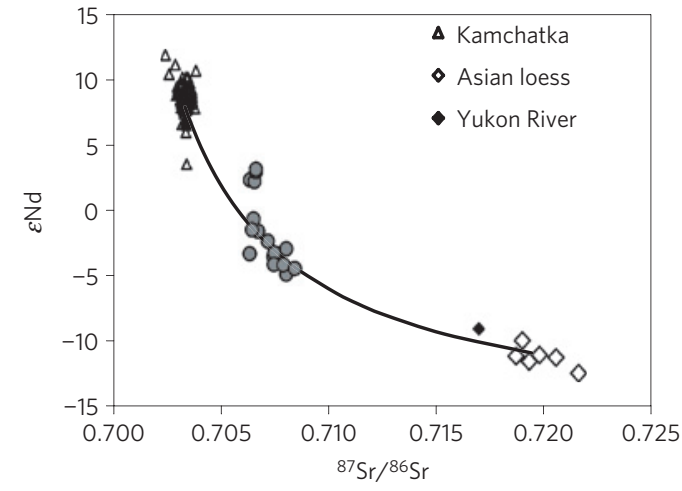

c

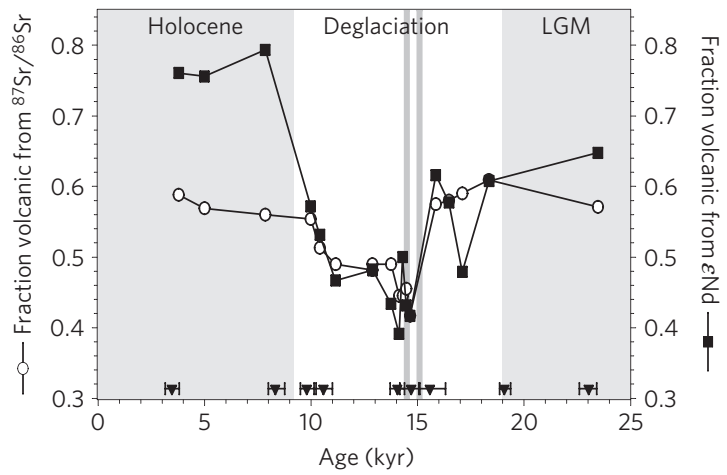

Figure 1 | Detrital provenance reconstructions based on Sr and Nd isotopic composition. $\mathbf{a},{ }^{87} \mathrm{Sr} /{ }^{86} \mathrm{Sr}$ (circles) and $\varepsilon \mathrm{Nd}$ (squares) downcore in GGC-37. b, The theoretical mixing line (black curve) between Kamchatka volcanic (triangles) and loess-like (diamonds) endmembers, with GGC-37 detrital fraction (circles). c, The fraction of volcanic-like detrital material over time, from $\varepsilon \mathrm{Nd}$ (squares) and ${ }^{87} \mathrm{Sr} /{ }^{86} \mathrm{Sr}$ (circles). Grey shading indicates Holocene and LGM periods. Vertical grey lines indicate the productivity pulse $13.8 \mathrm{kyr}$ ago and rapid drop in $\delta^{18} \mathrm{O}$ of planktonic foraminifera $14.4 \mathrm{kyr}$ ago. Filled black triangles on the $x$ axis in a denote the depth of radiocarbon dates with median calendar age and in $\mathbf{c}$ denote the median calendar age with $1 \sigma$ errors.

throughout most of the deglaciation and drops by a factor of 4-5 between the LGM and the Holocene (Fig. 2d).

Atmospheric modelling shows much stronger winds coming from the Bering Sea area during the LGM (Fig. 3). We postulate that an additional subaerial supply of detritus from the exposed Bering Sea shelf during the low sea-level stand supplemented the increase in Asian loess that has been simulated for the LGM (ref. 10). The decrease in loess-like flux $11 \mathrm{kyr}$ ago coincides with the flooding of the Bering Strait ${ }^{17}$, suggesting that subaerial delivery of exposed Bering Shelf sediments contributed primarily to the flux of loess-like material to our core before the deglaciation.
Modern volcanic material is from continental margin sediments ${ }^{7}$ or volcanic ash ${ }^{9}$. Enumeration of volcanic ash shards and ice rafted debris in RAMA 44PC, a nearby core on the Meiji Seamount, $360 \mathrm{~km}$ northwest of GGC-37 (Fig. 3), showed rare ash content but high ice-rafted debris in the LGM and early deglaciation (Supplementary Fig. S1), suggesting the ice-rafted transport of volcanic-like detritus from the surrounding margins. Sediment provenance studies on the nearby Meiji Drift on the eastern flank of the Emperor Seamounts suggest higher deep-boundary current velocities from the Bering Sea during glacial times ${ }^{14}$, perhaps supplying additional volcanic-like material to GGC-37 from the Kamchatka Strait that would be decoupled from a subaerial Bering shelf source.

Like other locations across the North Pacific ${ }^{1}$, all productivity proxies in GGC-37 show a well-defined maximum 14.2-13.8 kyr ago (Fig. 2e-i). The ${ }^{230}$ Th-normalized carbonate flux is higher in the Holocene compared with the LGM. Authigenic U was high during the LGM, probably owing to reduced oxygen levels from decreased ventilation of abyssal waters rather than increased flux of organic matter ${ }^{18,19}$. The opal flux during the Holocene seems to be biased low by poor opal preservation, as ${ }^{231} \mathrm{~Pa}_{\mathrm{xs}} /{ }^{230} \mathrm{Th}_{\mathrm{xs}}$, which is expected to track opal flux but not opal dissolution ${ }^{20}$, is higher in the Holocene compared with the LGM. Overall, the productivity proxies in this and other cores suggest that productivity was highest at the mid-deglacial peak, lowest during the LGM and at intermediate levels in the Holocene ${ }^{1}$.

There is no correlation between the records of detrital/iron flux (Fig. 2c) and those of the palaeoproductivity proxies (Fig. 2e-i). During the LGM, when iron fluxes were highest, productivity was lowest; further, there was no clear pulse in iron supply around the time of the $14 \mathrm{kyr}$ productivity peak from either a volcanic-like or loess-like source (Fig. 2d and Supplementary Fig. S1). These data indicate that rising sea levels did not, as previously hypothesized ${ }^{2}$, lead to an increase in iron from flooding volcanic margins in the WSP. Indeed, the area flooded during Meltwater Pulse la (ref. 21) is small (Fig. 3c) owing to the steep and narrow continental margins in the WSP. Unlike the modern day, when iron is an established control of productivity in the subarctic Pacific, the glacial and deglacial productivity must have been controlled by other factors.

A lower major nutrient supply from increased stratification has been suggested to explain the low LGM productivity ${ }^{18}$. The LGM was thought to have nutrient-depleted intermediate waters compared with the modern ${ }^{12}$, so deeper winter mixing would not replenish the surface with nutrients from below, leading to nutrient limitation (Fig. 4). The deglacial productivity peak has, by extension, been explained by increased nutrient supply from a breakdown in stratification ${ }^{19}$, but the timing of the stratification breakdown seems to precede the productivity peak by several thousand years in the WSP (ref. 22). Indeed, the decrease in nutrient utilization as suggested by the decline in $\delta^{15} \mathrm{~N}_{\mathrm{db}}$ in the early deglaciation (15-18 kyr ago; Fig. $2 \mathrm{j}$ ) while the productivity remains low (Fig. $2 \mathrm{e}-\mathrm{i}$ ) suggests an inability of phytoplankton to use the increased nitrate supply owing to another limiting factor. Given that the iron flux is still high at this time (Fig. 2c), iron limitation is an unlikely explanation for this decrease in nutrient utilization. Modelling studies have suggested that freshwater input to the North Atlantic in the early deglaciation could have triggered deep convection in the North Pacific ${ }^{23}$ and observations constrain the depth of this convection to be between 1,400 and $2,300 \mathrm{~m}$ (ref. 24). Such convection would increase nitrate supply to surface waters, but by greatly deepening the mixed layer, would also severely reduce the light availability for phytoplankton growth (Fig. 4). The continued low productivity despite high nitrate and iron supply in the early deglaciation can thus be explained by light limitation of productivity, such as would occur if the mixed layer were always deeper than the critical depth ${ }^{25}$ (Fig. 4). 


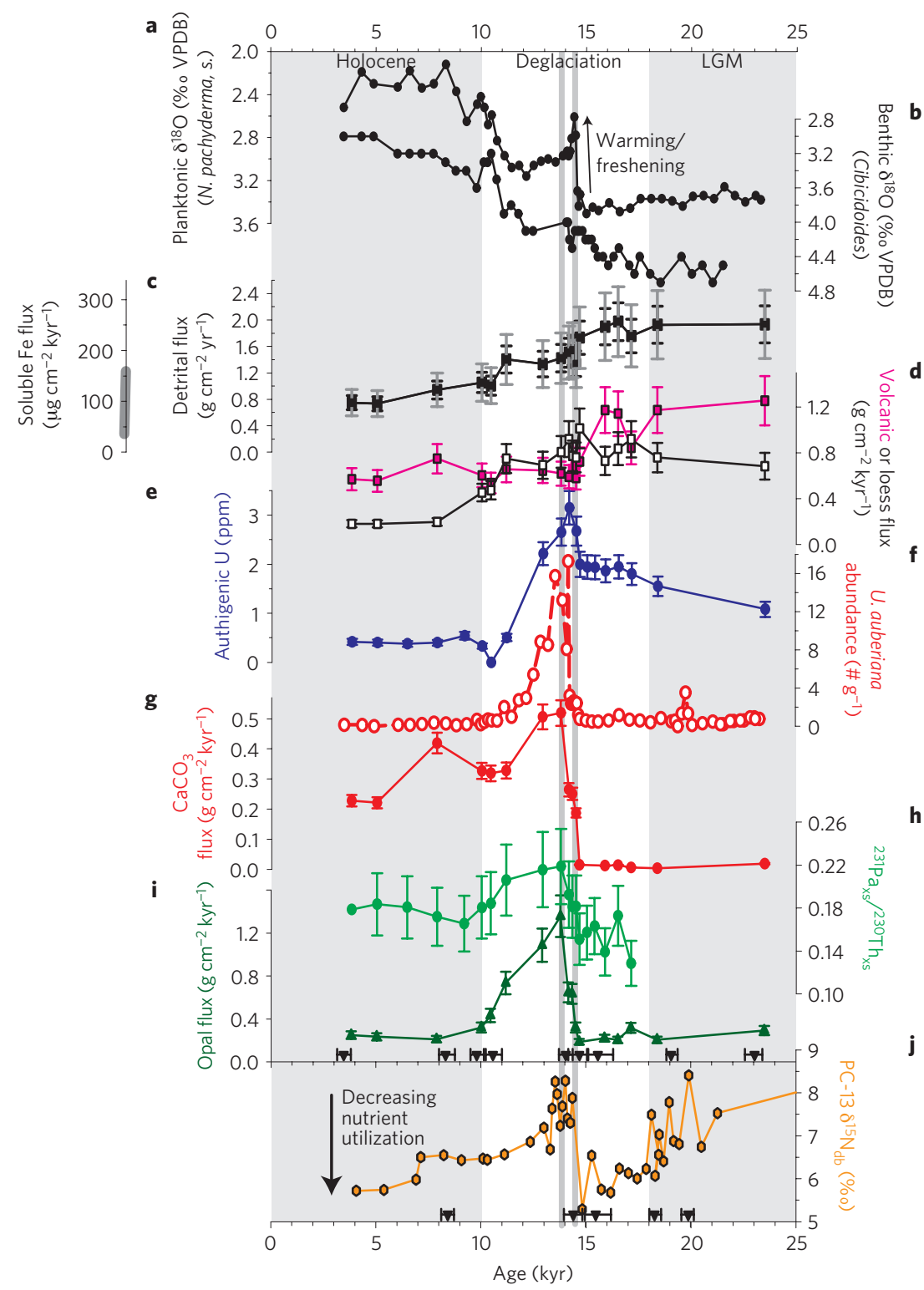

Figure 2 | Multiproxy downcore records. Data are from cores GGC-37 (a-i) and PC-13 (j). $\delta^{18} \mathrm{O}$ of planktonic ${ }^{12}$ (a) and benthic (b) foraminifera ${ }^{12}$. Detrital flux (c; black, errors) and equivalent soluble iron flux (grey, errors). Estimates of pre-industrial soluble iron flux to WSP (vertical grey bar on soluble Fe flux axis) $)^{6}$. Detrital flux (d) from volcanic-like (pink) and loess-like (white) sources determined from $\varepsilon$ Nd. Multiple proxies of palaeoproductivity are authigenic

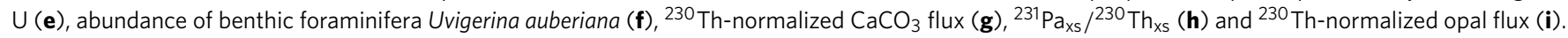
$\delta^{15} \mathrm{~N}$ of diatom-bound organic matter from core PC-13 (ref. 22) is shown in (j). Shading, vertical lines and radiocarbon dates (filled black triangles) and errors as in Fig. 1c. Vertical error bars, $2 \sigma$.

Around $14.5 \mathrm{kyr}$ ago, there is a rapid decrease in the oxygen isotope ratio of planktonic foraminifera (Fig. 2a), consistent with a rapid warming and/or freshening of surface waters, which is followed immediately by the deglacial productivity peak (Fig. 2e-i). The same decrease in planktonic $\delta^{18} \mathrm{O}$ around $14.5 \mathrm{kyr}$ ago is seen in cores across the North Pacific ${ }^{2,19,26}$ and is consistent with an input of meltwater to the North Pacific from the Cordilleran Ice Sheet $^{2}$. Such a freshwater pulse would increase stratification of the upper ocean. The high nitrate mixed in from the deep convection would be trapped in the shallow, high-light mixed layer and, when coupled with the high iron flux supplied from above, could set up ideal conditions for the deglacial primary production peak (Fig. 4). Without deep convection, the high nutrient concentrations in intermediate waters would decrease and, together with declining iron flux, contribute to a decrease in productivity towards Holocene levels. The low nutrient utilization (low $\delta^{15} \mathrm{~N}_{\mathrm{db}}$ ) in the Holocene is thus due to iron limitation, whereas it is due to light limitation in the early deglaciation (Fig. $2 \mathrm{j}$ ). The deglacial productivity peak is thus a transient response to the shutting down of relatively deep convection in the Pacific at a time of moderately high iron supply.

The subarctic Pacific and the Antarctic Southern Ocean both exhibited lower productivity during glacial times because increased stratification reduced major nutrient supply to the euphotic zone $e^{27}$. Although both regions exhibited a breakdown in stratification on exiting the glacial age, the productivity response of each seems to be different. In the Antarctic Southern Ocean, an early deglacial increase in ventilation ${ }^{28}$ and wind-driven major nutrient supply was immediately manifested in increased opal fluxes ${ }^{20}$, suggesting that the supply of major nutrients exerted the first-order control on increased productivity in the deglaciation. The Southern Ocean has a built-in mechanism for springtime stratification in the form of seasonal melting of sea ice ${ }^{29}$, moderating the deep convection that 
a
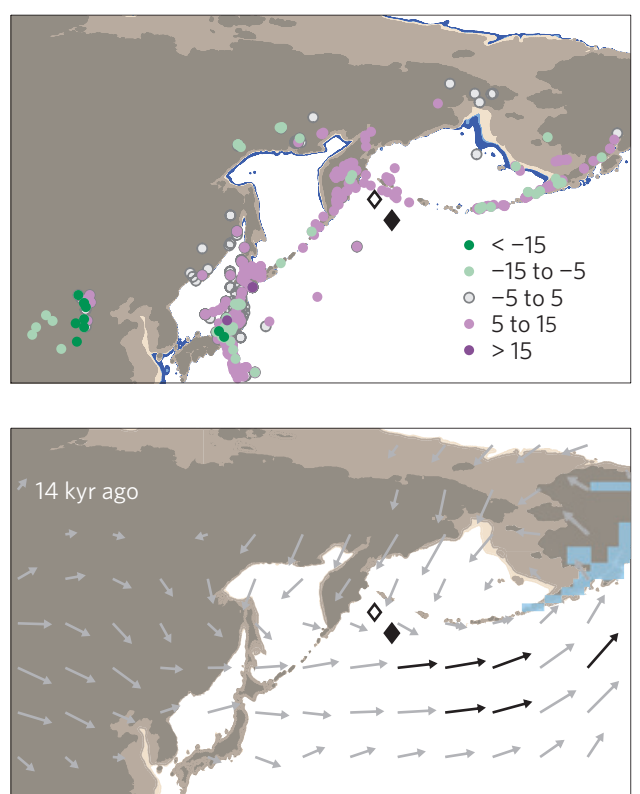

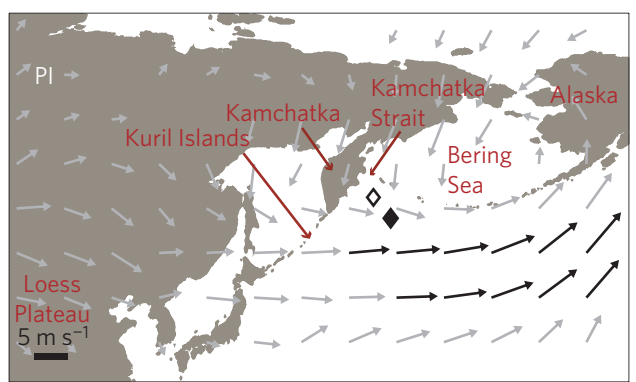

d

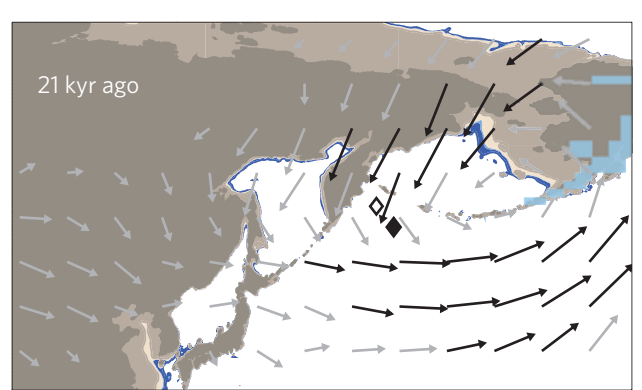

Figure 3 | Map of study area showing endmember $\varepsilon$ Nd, modelled wind and sea level at key climate periods. a, $\varepsilon$ Nd of detritus (dots). b-d, Modelled annual mean surface winds (arrows) from the pre-industrial (PI, b), mid-deglaciation ( 14 kyr ago, c) and LGM (21 kyr ago, d). Black arrows indicate winds $>5 \mathrm{~m} \mathrm{~s}^{-1}$. Coastline shading: PI ( $\left.0 \mathrm{~m}\right)$ in dark brown; deglacial after (72 mbp, metres below present) and before (90 mbp) Meltwater Pulse 1a in light brown and tan, respectively; LGM (120 mbp) in dark blue ${ }^{21}$. Bathymetry contours from ETOPO1. Light blue shading 14 kyr ago and $21 \mathrm{kyr}$ ago is the modelled extent of continental ice sheets. Locations of the GGC-37 and PC-13 (filled diamond) and RAMA44PC (open diamond) cores are indicated.

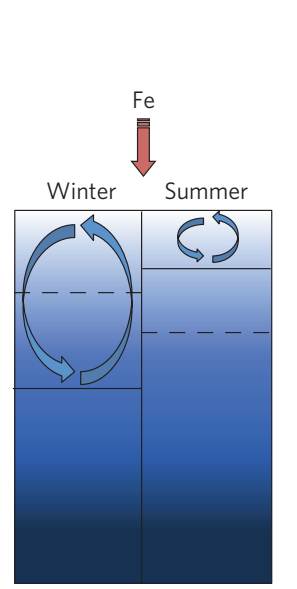

Holocene Low productivity

Fe limited

Moderate $\mathrm{NO}_{3}$

Low Fe

High light

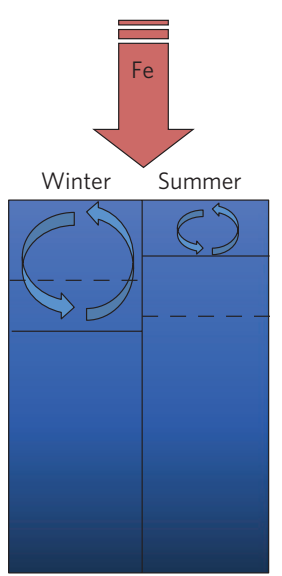

14 kyr ago, meltwater pulse High productivity Bloom conditions $\mathrm{High} \mathrm{NO}_{3}$ Moderate Fe High light

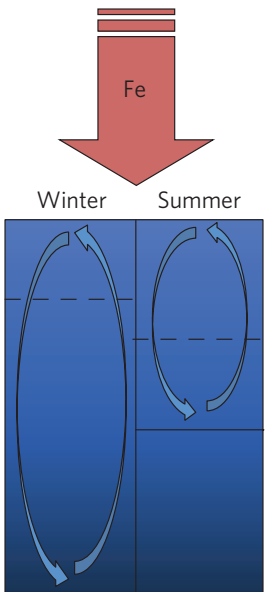

kyr ago, deep convection Low productivity Light limited High $\mathrm{NO}_{3}$ High Fe Low light

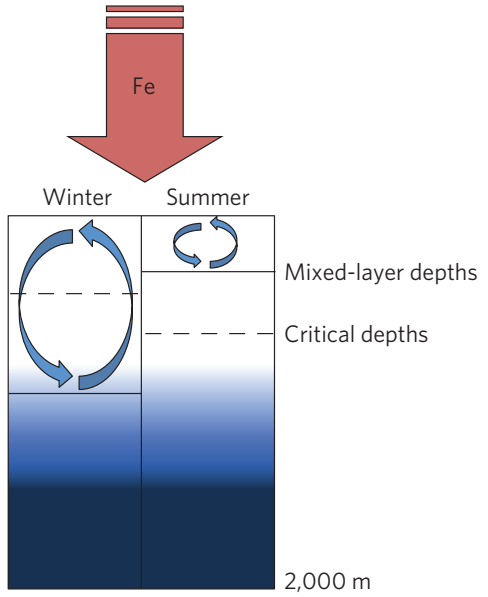

LGM, deep stratification

Low productivity

Nutrient limited

Low $\mathrm{NO}_{3}$

High Fe

High light

Figure 4 | Schematic to illustrate vertical mixing, nutrient and light levels during the Holocene, mid-deglaciation (14 kyr ago), early deglaciation (18 kyr ago) and during the LGM. Shading represents nitrate concentrations (dark is high). Mixed-layer depths (solid horizontal lines, deeper in winter) below the critical depth (dashed horizontal lines, shallower in winter ${ }^{25}$ ) result in light limitation of productivity. During the LGM, nutrient-depleted intermediate waters lead to nutrient limitation. Deep convection $18 \mathrm{kyr}$ ago increases nutrient supply to the surface, but also leads to light limitation. Meltwater-induced stratification $14 \mathrm{kyr}$ ago traps high nutrients and moderate iron in a high-light environment, leading to high productivity. During the Holocene, atmospheric Fe flux has decreased, leading to the modern situation of Fe limitation.

would limit productivity. In contrast, the sea surface temperature of the subarctic Pacific never approached freezing, even during the height of the LGM (ref. 18). Our work suggests that without the effect of seasonally melting sea ice, the stratifying influence of an additional meltwater pulse was required in the subarctic Pacific to moderate the low light from deep mixing and thus allow a productivity pulse. Although iron clearly controls production in the three modern-day high-nutrient, low-chlorophyll regions, it seemed to have played second (or third) fiddle to major nutrient and light supply in the deglacial subarctic Pacific and Antarctic Southern Ocean.

\section{Methods}

We measured U-series isotopes to determine authigenic uranium, ${ }^{231} \mathrm{~Pa} /{ }^{230} \mathrm{Th}$ and ${ }^{230} \mathrm{Th}$-normalized fluxes of opal, carbonate and detritus, and also determined the 
dry-mass normalized abundance of the benthic foraminiferal species Uvigerina auberiana on GGC-37. Previously published $\delta^{18} \mathrm{O}$ and benthic foraminiferal abundance measurements ${ }^{12}$ were made on subsamples taken from the working half of core GGC-37. All other measurements were made on subsamples taken from the archive half of core GGC-37 and corrected for a four-centimetre offset between the working and archive halves. The age model for GGC-37 is based on nine out of a total of 13 radiocarbon measurements on planktonic foraminifera and converted to calendar age with Calib 6.0, using a constant reservoir age anomaly $(\Delta \mathrm{R})$ of $370 \pm 250$ years. The $\delta^{15} \mathrm{~N}$ of diatom-bound organic matter from core PC-13 was previously published ${ }^{22}$, but we recalibrated the radiocarbon ages to be consistent with GGC-37.

We used the $\mathrm{Sr}$ and $\mathrm{Nd}$ isotopic composition of the residual fraction following sequential leaching to determine the provenance of detrital material to the core location over time. We converted detrital to soluble iron fluxes by conducting leaching experiments on Chinese loess and crushed basalt from two Kuril-Kamchatka volcanoes to determine the amount of iron released from each potential source rock. We used surface wind from simulations of LGM (21 kyr ago), deglacial (14 kyr ago) and pre-industrial climates carried out by the Community Atmosphere Model, version 3. More details for all methods are in the Supplementary Information. The data reported here are tabulated in Supplementary Information S1 and S2 and will be archived in the US National Oceanic and Atmospheric Administration palaeoclimatology database.

\section{Received 15 March 2013; accepted 4 June 2013; published online} 14 July 2013

\section{References}

1. Kohfeld, K. E. \& Chase, Z. Controls on deglacial changes in biogenic fluxes in the North Pacific Ocean. Quat. Sci. Rev. 30, 3350-3363 (2011).

2. Davies, M. H. et al. The deglacial transition on the southeastern Alaska Margin Meltwater input, sea level rise, marine productivity, and sedimentary anoxia. Paleoceanography 26, PA2223 (2011).

3. Boyd, P. W. et al. Mesoscale iron enrichment experiments 1993-2005: Synthesis and future directions. Science 315, 612-617 (2007).

4. Murray, R. W., Leinen, M. \& Knowlton, C. W. Links between iron input and opal deposition in the Pleistocene equatorial Pacific Ocean. Nature Geosci. 5, 270-274 (2012).

5. Kienast, S. S., Hendy, I. L., Crusius, J., Pedersen, T. F. \& Calvert, S. E. Export production in the subarctic North Pacific over the last 800 kyrs: No evidence for iron fertilization? J. Oceanogr. 60, 189-203 (2004).

6. Mahowald, N. M. et al. Atmospheric iron deposition: Global distribution, variability, and human perturbations. Annu. Rev. Mar. Sci. 1, 245-278 (2009).

7. Lam, P. J. \& Bishop, J. K. B. The continental margin is a key source of iron to the HNLC North Pacific Ocean. Geophys. Res. Lett. 35, L07608 (2008).

8. Nishioka, J. et al. Iron supply to the western subarctic Pacific: Importance of iron export from the Sea of Okhotsk. J. Geophys. Res. 112, C10012 (2007).

9. Hamme, R. C. et al. Volcanic ash fuels anomalous plankton bloom in subarctic northeast Pacific. Geophys. Res. Lett. 37, L19604 (2010).

10. Mahowald, N., Albani, S., Engelstaedter, S., Winckler, G. \& Goman, M. Model insight into glacial-interglacial paleodust records. Quat. Sci. Rev. 30, 832-854 (2011).

11. Otosaka, S., Honda, M. C. \& Noriki, S. La/Yb and Th/Sc in settling particles: Vertical and horizontal transport of lithogenic material in the western North Pacific. Geochem. J. 38, 515-525 (2004).

12. Keigwin, L. D. Glacial-age hydrography of the far northwest Pacific Ocean. Paleoceanography 13, 323-339 (1998).

13. Yokoo, Y., Nakano, T., Nishikawa, M. \& Quan, H. Mineralogical variation of Sr-Nd isotopic and elemental compositions in loess and desert sand from the central Loess Plateau in China as a provenance tracer of wet and dry deposition in the northwestern Pacific. Chem. Geol. 204, 45-62 (2004).

14. VanLaningham, S., Pisias, N. G., Duncan, R. A. \& Clift, P. D. Glacial-interglacial sediment transport to the Meiji Drift, northwest Pacific Ocean: Evidence for timing of Beringian outwashing. Earth Planet. Sci. Lett. 277, 64-72 (2009).
15. Millot, R., Gaillardet, J. é, Dupré, B. \& Allègre, C. J. Northern latitude chemical weathering rates: Clues from the Mackenzie River Basin, Canada. Geochim. Et Cosmochim. Acta 67, 1305-1329 (2003).

16. Kohfeld, K. E. \& Harrison, S. P. DIRTMAP: The geological record of dust. Earth-Sci. Rev. 54, 81-114 (2001).

17. Keigwin, L. D., Donnelly, J. P., Cook, M. S., Driscoll, N. W. \& Brigham-Grette, J. Rapid sea-level rise and Holocene climate in the Chukchi Sea. Geology 34, 861-864 (2006).

18. Jaccard, S. L. et al. Glacial/interglacial changes in subarctic north pacific stratification. Science 308, $1003-1006$ (2005).

19. Galbraith, E. D. et al. Carbon dioxide release from the North Pacific abyss during the last deglaciation. Nature 449, 890-893 (2007).

20. Anderson, R. et al. Wind-driven upwelling in the Southern Ocean and the deglacial rise in atmospheric CO2. Science 323, 1443-1448 (2009).

21. Stanford, J. et al. Sea-level probability for the last deglaciation: A statistical analysis of far-field records. Glob. Planet. Change 79, 193-203 (2011).

22. Brunelle, B. G. et al. Glacial/interglacial changes in nutrient supply and stratification in the western subarctic North Pacific since the penultimate glacial maximum. Quat. Sci. Rev. 29, 2579-2590 (2010).

23. Hu, A. et al. The Pacific-Atlantic seesaw and the Bering Strait. Geophys. Res. Lett. 39, L03702 (2012).

24. Jaccard, S. L. \& Galbraith, E. D. Direct ventilation of the North Pacific did not reach the deep ocean during the last deglaciation. Geophys. Res. Lett. 40, 199-203 (2013).

25. Obata, A., Ishizaka, J. \& Endoh, M. Global verification of critical depth theory for phytoplankton bloom with climatological in situ temperature and satellite ocean color data. J. Geophys. Res. 101, 20657-20667 (1996).

26. Keigwin, L. D., Jones, G. A. \& Froelich, P. N. A 15,000 year paleoenvironmenta record from Meiji Seamount, far northwestern Pacific. Earth Planet. Sci. Lett. 111, 425-440 (1992).

27. Haug, G. H. \& Sigman, D. M. Palaeoceanography: Polar twins. Nature Geosci. 2, 91-92 (2009).

28. Burke, A. \& Robinson, L. F. The Southern Ocean's role in carbon exchange during the last deglaciation. Science 335, 557-561 (2012).

29. Roche, D. M., Crosta, X. \& Renssen, H. Evaluating Southern Ocean sea-ice for the Last Glacial Maximum and pre-industrial climates: PMIP-2 models and data evidence. Quat. Sci. Rev. 56, 99-106 (2012).

\section{Acknowledgements}

This work was supported by the Lawrence J. Pratt and Melinda M. Hall Endowed Award for Interdisciplinary Research to L.F.R., P.J.L. and J.B.; the Marie-Curie Reintegration programme, European Research Council no. 278705 to L.F.R.; National Science Foundation (NSF) to P.J.L.; the Centre for Climate Dynamics at the Bjerknes Centre to C.L.; the Comer Science and Education Fund and the US NSF to J.F.M.; and NSF OCE-1031224 to L.D.K. Thanks to J. Goudreau for U-series help, E. Crapster-Pregont, J. Swartz, D. Ohnemus and M. Auro for sediment leaches, M. Carman for assistance with foraminiferal abundance counts, C. M. Bitz for providing ocean boundary conditions for the $14 \mathrm{kyr}$ simulation and C. Lamborg, J. Rae and A. Mahadevan for stimulating discussions. This is publication no. A423 from the Bjerknes Centre for Climate Research.

\section{Author contributions}

P.J.L., L.F.R. and J.B. conceived the project. L.F.R. conducted U-series measurements; J.B. conducted $\mathrm{Nd}$ and $\mathrm{Sr}$ isotope measurements; C.L. provided G.C.M. output; J.F.M. measured sediment composition; M.S.C. provided the age model and foraminiferal abundances; L.D.K. provided volcanic ash shard counts; P.J.L. measured soluble Fe and wrote the paper; all helped with interpretations and commented on the manuscript.

\section{Additional information}

Supplementary information is available in the online version of the paper. Reprints and permissions information is available online at www.nature.com/reprints. Correspondence and requests for materials should be addressed to P.J.L.

\section{Competing financial interests}

The authors declare no competing financial interests. 